\title{
Editorial Reflections
}

\section{J. Blake Scott and Lisa Melonçon}

Our introductions across the first two volumes of $R H M$ have consistently included reflections on our goals and journey as editors, and on the directions of the journal and growing field of RHM. As part of the issue that marks the journal's third year of publication, and that also marks the start of our fifth year of developing the journal, this introduction affords an especially opportune occasion for reflection.

Accordingly, we want to use this introduction to synthesize and extend our reflection about the journal and our editorial practice by sharing with you some of the things that we are most proud of and must remain attentive to: some (but not all) of the emergent topics taken up by conversations in the journal, some things to consider if you want to publish in $R H M$, and some future goals as we begin to move toward transitioning to new $R H M$ editors.

\section{Achievements and Ongoing Considerations}

From the earliest planning stages for the journal, we have given a great deal of thought to the processes involved in editing a journal. Specifically, we wanted to intervene and change practices by productively responding to common problems of structure and practice in academic publishing. As discussed in the introductions to issues 1.3-4 and 2.3, in particular, we have embraced a transparent and inclusive ethos as editors. This had led to a number of resources, practices, and structures that we are proud of, including the following:

(C) 2020 University of Florida Press 


\section{Editors' Introduction}

-We have created an editorial leadership team that includes associate and assistant editors, a managing editorial assistant and interns, and an editorial board from various fields, institution types, and career stages;

- We sponsor training and professional development opportunities for other scholars, most importantly by inviting junior scholars to coedit special issues of the journal in an apprenticeship model (see http://journals.upress.ufl.edu/rhm/announcement/view/9);

- To supplement submission instructions to authors, we have created a series of open-access videos that explain key aspects of the journal's processes (on the journal's website), with topics, including our review process and decision letters, how the journal defines "rhetoric," submission types, and author interviews;

- Our managing editorial assistant has created documentation for all of our internal processes, including the layers of review and editing;

- We work extensively to help prospective authors develop manuscripts before and after submission to the journal, which involves answering follow-up questions about our detailed decision letters and revision directions;

- We supplement the regular content of each issue with additional video/written interviews with authors that provide "behind-thescenes" explanations of research processes and/or implications for other health/medical stakeholders;

- We publish a range of genre types beyond research articles, including dialogues, commentaries, review essays, bibliographic essays, "persuasion briefs" or white papers of rhetorical research for other audiences, and more recently, "ethical exposure" essays that explicitly take up ethical quandaries and conundrums encountered and negotiated in research practices.

In addition to these practices toward transparency and inclusion, we are proud of the following accomplishments:

- Because of the flexibility of our publisher (thank you, UF Press) and a steady stream of submissions, we were able to transition from two double issues per year to four quarterly issues after just one year;

- Using a double-anonymous peer review process, we have a rigorous acceptance rate of below 14\%, an 8-week maximum turnaround from 
submission to decision, and detailed decision-letters that a number of submitting writers (including those with manuscripts rejected) have praised as among the most helpful they've received;

- Although the journal began in 2018, it is already included in several key journal indexes (e.g., Project Muse, ProQuest, Academic OneFile, Academic Search Ultimate, Health Reference Center Academic);

- Along with a number of other manuscript development efforts, we have tied the journal to a biennial national/international Rhetoric of Health \& Medicine Symposium at which faculty and graduate students workshop their work with the goal of submitting to RHM or elsewhere.

All of this has been possible because of you - the vibrant and growing community of RHM scholars who were the catalyst for this crowdsourced endeavor and who continue to sustain it-especially by submitting your important work. It has also been possible, of course, thanks to our stellar editorial board, editorial team, and reviewers. We have been so impressed by the consistent care and detail of the reviews that we have received that we will begin giving annual review awards, with the vol. 2 awards being announced in issue 3.2.

We are pleased to announce that these achievements have been recognized by a national award- the 2019 Best New Journal Award from the Council of Editors of Learned Journals (CELJ), an affiliate of the Modern Language Association. It has been more than 10 years since a journal in rhetoric or writing studies won this award.

We are not content to rest on this laurel, however. As we've written earlier (e.g., intro of issue 2.3), we are actively working to further diversify our editorial board, reviewer pool, genre types, and topics, the latter through continued "ethical exposure" essays, open calls for special issues that address underrepresented topics, and a review process that encourages writers to take chances even while situating their work in ways that continue existing conversations.

\section{Considerations for Publishing in RHM}

As we have continued to read and synthesize reviews, we have further identified common patterns of limitations across submissions that are declined 


\section{Editors' Introduction}

or undergo multiple rounds of major revision. In an effort to aid submission development and success, we wanted to briefly mention some of these patterns here.

Still the two most common reasons manuscripts get declined are 1) little to no connection to relevant RHM conversations (broadly defined) and discussion of broader implications for RHM scholarship, and 2) a surface level focus on the rhetorical dimensions and functions of the discourse or phenomena being analyzed, usually accompanied by a lack of rhetorical theory (also broadly defined) to inform the analysis. This second limitation is why we created the video explaining how the journal and the work we publish is rhetorical. We've previously discussed (in the intro to issue 1.3-4) how establishing and growing a field like RHM requires both alignment and imagination, and our reviewers have expertly enacted this by ensuring that submitting writers acknowledge and connect their work to existing RHM conversations while also bringing in relevant scholarship outside of the field. This latter move can help expand the citation patterns of the field in more inclusive, but also reinforcing, directions.

Probably the third most common limitation noted by us and the reviewers, and one related to a journal point of emphasis named above, is an inadequate explanation of the methodology. We expect submissions to describe, explain, and provide a rationale for the theoretical framework and methodological orientation, methods, and practice-level, situational decisions, and we are committed to giving space in the journal for such discussion.

Other common limitations include the following:

- Methods such as ill-defined or formulaic close readings that do not advance methodology and/or seem inadequately suited for the inquiry and phenomena under study;

- Analyses that do not seem adequately informed by and connected to the theoretical framework and methodology;

- Analyses that require additional specific support for and in-depth explanation of the points being made;

- Organizational structures that make it difficult to discern the primary argument and its stakes or that require streamlining of background information and/or integration of the "literature review";

- Arguments that are too general to make useful contributions or not nuanced and qualified enough to be supported by the analyses. 
We point to these areas as yet another way of opening up and making more transparent the review and decision process. By summarizing these common areas, we hope that prospective authors can better position their work because they have a better sense of the what the focus and scope of the journal means in practice.

\section{Continued Emphases and Emergent Conversations}

As we state in the journal's Focus and Scope, $R H M$ is a multidisciplinary rhetoric journal. We publish work that uses "theories of rhetoric [or persuasion] to guide inquiry and arrive at nuanced observations about how persuasion works (or could/should work) in discourse and practice," and we also seek to advance "scholarly conversations about health and medicine across fields of inquiry and spheres of practice, in part by publishing interand transdisciplinary research." Another way we advance this type of reach is by publishing work with intended audiences that include, but also extend beyond rhetoricians, and then working with authors to promote this work with those audiences. The persuasion briefs, commentaries, dialogues, and research articles across the first two volumes provide good examples of rhetorically focused scholarship that draws from other fields and speaks to other audiences, such as physicians and other providers, translators, public health officials, policymakers and regulators, medical researchers, patient groups and their families, and patient and caregiver advocates.

From the outset, we have encouraged methodological explicitness and experimentation in the pieces we publish. We want $R H M$ to be a scholarly space where methodologies, in their various dimensions and often messy enactments, are perspicuously unpacked and highlighted, and also a space for featuring methodological innovation. These goals drove us to sponsor interviews with authors about their "behind-the-scenes" methodological decision-making, the "ethical exposure" series of essays, and commentaries and dialogues about a potential statement of ethics for RHM, along with the ethics of embodied research, community engagement, and other topics. Beyond such featured pieces, we prioritize this type of methodological explicitness in everything we publish.

Related to inter-/transdisciplinary research and methodological experimentation is another continuing emphasis of the journal-theory building. We and our reviewers work hard to help submitting authors develop 


\section{Editors' Introduction}

and highlight the kinds of methodological and theoretical contributions that are grounded in specific studies but can also be adapted for studies of other health and medical concerns and contexts.

Due in part to the expansiveness of our field and range of topics explored, RHM publications appearing in our journal and other places can sometimes seem disconnected from one another, even when they draw on previous work. We have been fortunate thus far that the manuscripts making it through review have created a number of consistent conversations, but we also note that we and the reviewers have encouraged this by helping authors more substantively and carefully engage other relevant work and by inviting submissions around common topics through featured sections and special issues.

Figure 1 is a word cloud based on the abstracts and keywords from the first two years of $R H M$ scholarship. It begins to show some of the topics consistently taken up by authors.

Although we note that the slight prominence of "health" over "medicine" suggests attention to an expansive set of discourses and practices, we want to focus on less obvious combinations of terms. The combination of "research," "clinical," "policy," "public," "cultural," and "personal" also suggests a range of sites and concerns that our authors have engaged. Terms that could signify RHM's relations and relationships, the topic of

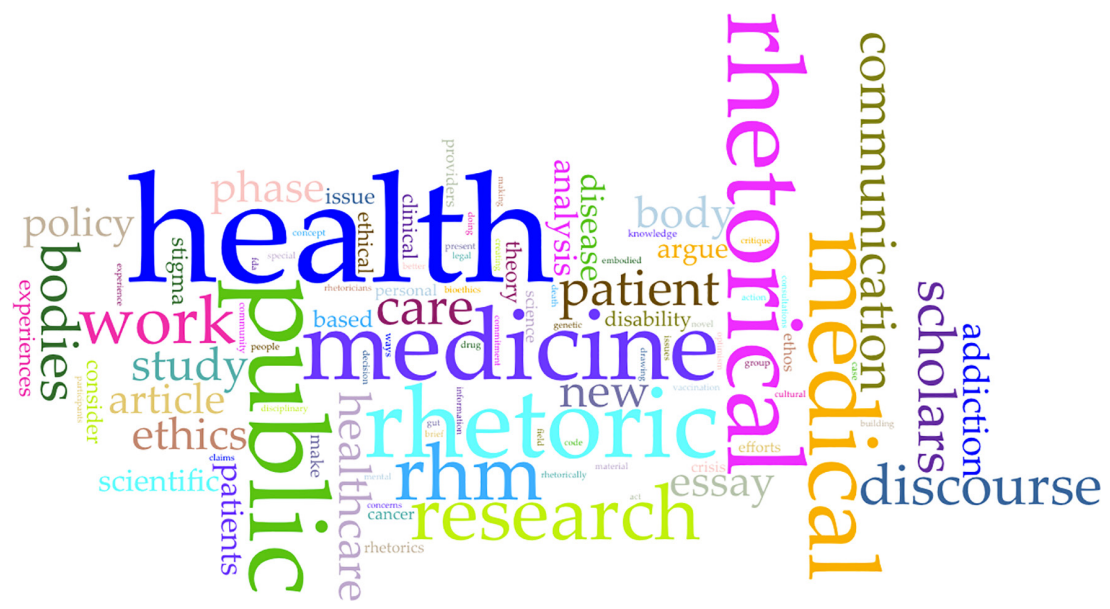

Figure 1. Word cloud based on the abstracts and keywords taken from the first two years of $R H M$ scholarship. 
our introduction in issue 2.4, include "science/scientific," "disability," and "bioethics." Other terms that stand out to us include "ethical"/"ethics" and "care," the latter suggesting a particular ameliorative orientation to the former cluster, along with other ethics-related topics such as "stigma," "addiction," "genetic," and "vaccination." Another cluster of words that stand to us include "body"/"bodies"/“embodied," "patient(s)," and "experience," which together point to the journal's attention to the embodied experiences of patients and others.

Beyond these broader topical clusters and patterns, we want to point out some more specific lines of inquiry across the journal's first two years, many of which relate to the topic of ethics. These include the following: 1) ethical considerations around engaging partners, participants, and publics/ communities in our rhetorical research practices; 2) the ethics of engaging patients in medical research, regulatory process, and public health efforts; 3) the politics of representation and responsibility in cultural discourses around wellness, illness, and dying; and 4) advantages and limitations of different cultural-rhetorical framings of bioethics.

Related to such lines of inquiry that focus more overtly on ethical questions are discussions of the complexity of health stakeholders' or actors' perspectives, motivations, and actions, including the following: 1) rhetorical responses to kakoethos, including tactics of "recuperative ethos" and noncompliance; 2) patient and community motivations for seeking, resisting, or otherwise responding to health or medical intervention; 3) communal, cultural, and political factors shaping perspectives and (self/other)understandings of health/wellness and disease/illness; and 4) ideological motivations and rhetorical limitations and affordances of stakeholder advocacy efforts.

Yet another more specific set of conversations sponsored by the journal focuses on more distributed and material forms of rhetorical action and agency emerging from and inflecting health and medical practices. This set of conversations includes: 1) the embodied, multi-sensory dimensions of research and other forms of engagement; 2) the agency of distributed networks of embodied actors; and 3) the rhetorical capacities of non-human actors.

We look forward to how future regular issues contribute to these and other lines of inquiry, and we remain committed to inviting, developing, and publishing special issues, focused sections, and featured pieces that extend, reorient, and begin new conversations. Keep a look out for new 


\section{Editors' Introduction}

forms of persuasion briefs and dialogues, commentaries, and dialogues that take up RHM's relations and relationships with other areas, our first cluster of "ethical exposure" essays, follow-up pieces about the possibility of an RHM statement of ethics, and the special issue on mental health rhetoric.

\section{In This Issue}

This issue begins with two essays that nicely anticipate, from two different perspectives, our second special issue focused on mental health rhetoric that will appear later this year. First, we have Emily R. Johnston's rhetorical activity theory analysis of how the classification and cultural understandings of PTSD, the latter in popular media discourse, biomedicalize and pathologize the trauma associated with mass gun violence by defining it as an individual mental-psychological disorder requiring intervention. Focusing on the media coverage of the Las Vegas Shooting, Johnston explains how the rhetorical tension between alleviating and pathologizing gun violence trauma can exceptionalize and "shame survivors and commodify their pain" as a dysfunction.

In her study that also rhetorically analyzes the association of mass shootings with mental illness in popular media, Cassandra C. Kearney examines historical representations of the shooter rather than effects on contemporary survivors, focusing on what has been widely marked as the first mass shooting in the modern United States-the 1949 mass shooting by Howard Unruh in Camden, New Jersey. Employing an intertextual-textual reception analysis that draws on the work of Jenell Johnson and others, Kearney unpacks how representations of Unruh, including his "religious fanaticism" and physical appearance, "othered" him as being "schizophrenic" and "mad" in order to reassure and distance the public and avoid certain types of public policy responses to gun violence.

In this issue's third research article, Lauren Kolodziejski extends RHM work that seeks to better understand parents' perceptions of vaccinerelated risks and related decision-making, persuasively reinforcing more nuanced explanations for vaccine hesitancy and showing how such hesitancy has moved beyond a simple and explicit fear of autism. Based on a study involving semi-structured interviews with parents, Kolodziejski's article identifies three special topoi these parents draw on in their decisionmaking, topoi that are disconnected from those framing most public health 
vaccination efforts. This analysis enables Kolodziejski to offer specific ways to meet parents where they are, to help them adjust their "availability heuristic," or capacity to envision outcomes, in a way that speaks to their concerns.

This issue ends with a dialogue that, as we note above, continues conversations. As a true dialogue from a roundtable at a conference, we pushed the confines of our page limits to provide important insights into the complexities of doing community-based participatory research, as it intersects with the insider/outsider dilemma posed by Cathryn Molloy and colleagues in issue 1.3-4 and calls to mind some of the issues of working with communities raised by Laura Gonzales and Rachel Bloom-Pojar in the inaugural issue. While lengthy, this new dialogue synthesizes insights about approaches to CBPR from a diverse group of communication scholars, serving for some readers as a reminder of how to approach this research and for others as an accessible overview of the stakes, challenges, and joys of this type of research. More so, the voices in the dialogue also emphasize methodologies and methods in a different, yet important way and address the ongoing thread in much of RHM's work about the relationship between ethics and methodologies.

We also note two book reviews that we have now published on the journal website and repository site. Although we reserve regular journal space for fuller review essays (reviewing multiple works), we recognize the need for reviews of individual books and other genres and media, and we therefore plan to continue to develop these for online publication. The first is a review of Colleen Derkatch's Bounding Biomedicine: Evidence and Rhetoric in the New Science of Alternative Medicine by J. Blake Scott (see http://doi .org/10.5744/rhm.2020.1005). The second is a review of Elizabeth L. Angeli's Rhetorical Work in Emergency Medical Services: Communicating in the Unpredictable Workplace by Marissa C. McKinley (see http://doi.org/10 .5744/rhm.2020.1006).

We hope you enjoy this first issue of our third year. We will continue to be reflective editors, and we look forward to the next steps on this journey.

\section{References}

Angeli, Elizabeth. (2018). Rhetorical work in emergency medical services: Communicating in the unpredictable workplace. New York, NY: Routledge 


\section{Editors' Introduction}

Derkatch, Colleen. (2016). Bounding biomedicine: Evidence and rhetoric in the new science of alternative medicine. Chicago, IL: University of Chicago Press.

Gonzales, Laura, \& Bloom-Pojar, Rachel. (2018). A dialogue with medical interpreters about rhetoric, culture, and language. Rhetoric of Health $\mathcal{E}^{2} \mathrm{Medi}$ cine, 1(1-2), 193-212.

Molloy, Cathryn, Beemer, Cristy, Bennett, Jeffrey, Green, Ann, Johnson, Jenell, Kessler, Molly, Novotny, Maria, \& Siegel-Finer, Bryna. (2018). A dialogue on possibilities for embodied methodologies in the rhetoric of health \& medicine. Rhetoric of Health $\Xi^{\circ}$ Medicine, 1(3-4), 349-371. 